\title{
Propuesta de la policromía del Augusto de Prima Porta: hipótesis naturalista y metodología procedimental
}

\author{
Emma Zahonero Moreno, Jesús Mendiola Puig | Taller MV Arte \\ URL de la contribución <www.iaph.es/revistaph/index.php/revistaph/article/view/4596>
}

\section{RESUMEN}

La búsqueda del realismo-naturalista (fenomenológico) a través de la policromía de las producciones escultóricas marmóreas de época clásica implicaba la aplicación de diferentes capas de pintura, mediante conocidos procedimientos y técnicas pictóricas, que acababan de dotar a la obra esculpida de mayor realismo y verosimilitud. Diferentes investigaciones previas nos ayudaron a proponer una hipótesis sobre el aspecto polícromo de la escultura del emperador Augusto de Prima Porta en 2014. Las últimas investigaciones sobre policromía de esculturas romanas de todo el Mediterráneo y también de pinturas, de los conocidos como retratos de El Fayum, han confirmado nuestra hipótesis sobre los procedimientos pictóricos utilizados en las obras romanas de la época augústea, necesarios para lograr el buscado realismo naturalista.

\section{Palabras clave}

Augusto de Prima Porta | Esculturas conmemorativas | Mármol | Naturalismo | Pintura (Técnica) | Policromado (Técnica) | Realismo | Reconstrucción histórica | Taller MV Arte | Veladura (Técnica) | 


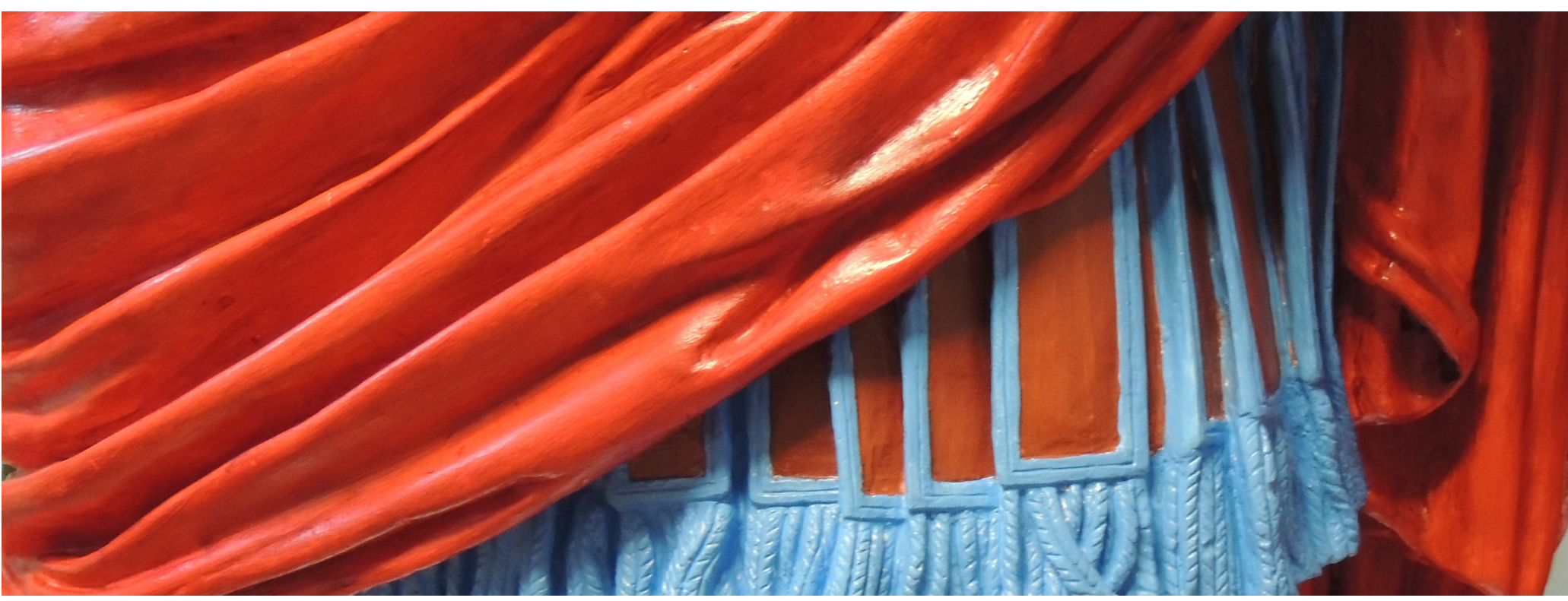

\section{Proposal of the polychromy of the Augusto de Prima Porta: naturalistic hypothesis and procedural methodology}

\section{ABSTRACT}

The search for the realism-naturalism (phenomenological) through the polychromy of the marble sculptural productions of the classical era involved the application of different layers of painting, through known procedures and pictorial techniques, which had just endowed the sculpted work of greater realism and likelihood. Different previous investigations helped us to propose a hypothesis about the polychrome aspect of the sculpture of Emperor Augustus of Prima Porta in 2014. The latest research, about polychromy of Roman sculptures from all over the Mediterranean and of paintings, known as portraits of El Fayum, have confirmed our hypothesis about the pictorial procedures used in the Roman works of augustean era, necessary to achieve the sought naturalistic realism.

\section{Keywords}

Augustus Prima Porta | Memorial sculptures | Marble | Naturalism | Painting (technique) | Polychrome (technique) | Realism | Historical reconstruction | Taller MV Arte | Glaze (technique) |

Cómo citar: Zahonero Moreno, E. y Mendiola Puig, J. (2021) Propuesta de la policromía del Augusto de Prima Porta: hipótesis naturalista y metodología procedimental. revista PH, n. ${ }^{\circ}$ 102, pp. 40-55. Disponible en: www.iaph.es/revistaph/index.php/revistaph/article/view/4596 DOI 10.33349/2021.102.4596

Enviado: 14/02/2020 | Aceptado: 26/08/2020 | Publicado: 10/02/2021 
A la izquierda, Augusto de Prima Porta, Museos Vaticanos | fuente Wikimedia Commons

En el centro, propuesta polícroma del Augusto de Prima Porta de Emma Zahonero y Jesús Mendiola | foto Taller MV Arte

A la derecha, Augusto del paseo arqueológico de Tarragona | foto Taller MV Arte

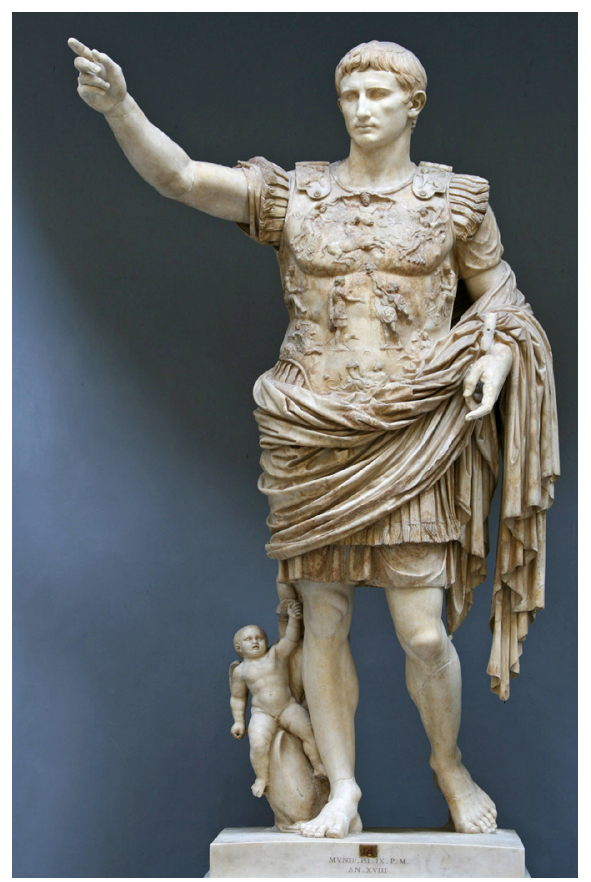

\section{INTRODUCCIÓN}

En el año 2014 los autores de este trabajo recibimos el encargo por parte del Museo de Historia de la Ciudad de Tarragona de realizar una copia a tamaño natural de la escultura del Augusto de Prima Porta para proponer una reconstrucción hipotética de su policromía perdida. La propuesta debía ser expuesta en el festival de reconstrucción histórica Tarraco Viva en el contexto de las actuaciones de celebración del bimilenario de la muerte del emperador Augusto que se desarrollaron ese año en la ciudad de Tarragona. Contábamos para ello con la escultura de bronce (procedente de un vaciado del original expuesto en los Museos Vaticanos) que fue regalada a las ciudades de Tarragona, Zaragoza y Mérida por las autoridades fascistas en el año 1934. Se trataba de realizar una copia de esta escultura de bronce hoy situada en el paseo arqueológico de las murallas de Tarragona y policromarla con los pigmentos, técnicas y procedimientos originales (Zahonero y Mendiola 2015).

Nuestra propuesta tenía como función: ilustrar al público en general, sin perder rigor histórico, sobre la práctica extendida en el mundo greco-romano de policromar las esculturas de forma realista-naturalista. Esta policromía embellecía aún más el fabuloso modelado que mostraban las esculturas en su presentación ante los ciudadanos: sombras que ayudan al volumen, elementos decorativos pintados a punta de pincel, veladuras o rayados entre colores que creaban nuevos y vibrantes tonos, combinaciones cromáticas
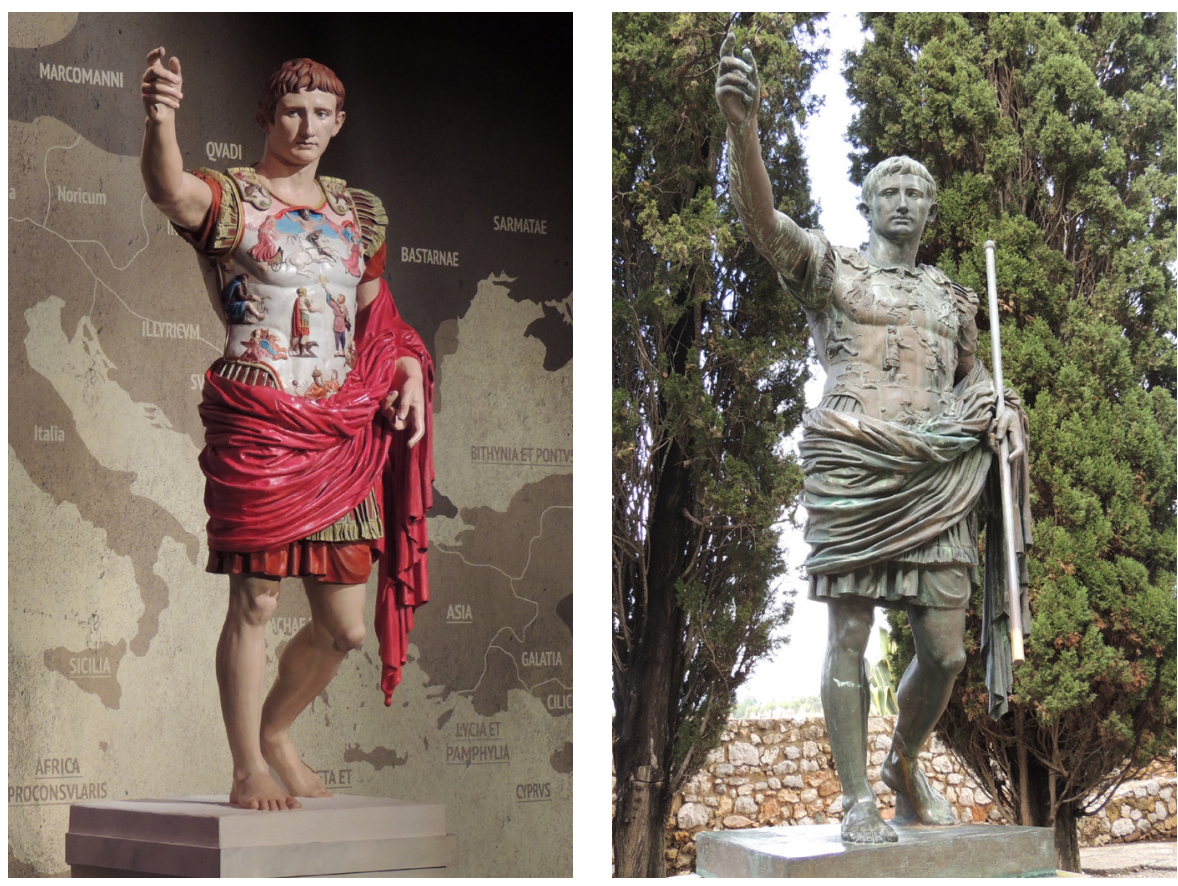
que simulaban metales y otros elementos artísticos que se utilizaban en la época y de los que tenemos constancia de forma documental, material y analítica (Zahonero 2013). Los autores de este trabajo somos licenciados en Bellas Artes, especialistas en conservación-restauración y nos dedicamos desde hace más de 25 años a la conservación-restauración de obras de arte y por ello, evidentemente también, a la investigación de las obras tratadas, las técnicas y sus procedimientos artísticos. Formamos parte a su vez del grupo de investigación SETOPANT, adscrito a la Universidad Rovira i Virgili de Tarragona y el ICAC.

\section{BUNTE GÖTTER/I COLORI DEL BIANCO. ESTUDIOS ANALÍTICOS Y PROPUESTAS CIENTÍFICAS SOBRE LA POLICROMÍA ESCULTÓRICA GRIEGA Y ROMANA}

Los templos griegos y sus esculturas decorativas estaban cubiertos de pintura, también las imágenes ofrendadas a los dioses en los santuarios. Así mismo lo estuvieron los templos y las esculturas de los romanos herederos de una tradición etrusca de templos arcaicos de madera y barro, revestidos de terracotas y con acróteras figurativas policromadas con engobes terrosos y más adelante colores variados. En el siglo XIX, los hallazgos evidentes de policromía en las imágenes votivas y fragmentos arquitectónicos en la acrópolis ateniense o en los frontones del templo de Atenea Aphaia en Egina transportados a Munich no dejaban lugar a dudas sobre esta cuestión, pero aun así la idea permanente de la blancura del mármol fue un concepto inherente a la sensación de "belleza clásica" que había impregnado en 1764 la Historia del Arte en la Antigüedad de H. Wynekelmann, perdurando hasta hoy en día en el imaginario europeo. Nada más lejano a la realidad. Las menciones explícitas de los textos antiguos, representaciones iconográficas realizadas sobre vasos áticos junto a las numerosas piezas artísticas que aún conservan evidencias de policromía o líneas de preparación para el diseño de la decoración pictórica, acreditan, de forma suficiente, la riqueza y variedad de la policromía en la arquitectura y la escultura griega y romana.

Los estudiosos del arte antiguo -historiadores del arte y arquitectos- en el siglo XIX plasmaron claramente en sus restituciones este universo de formas policromadas pero el visitante de los grandes museos europeos sigue dejándose llevar por la falsa impresión de las interminables filas blancas de esculturas y bustos labrados en mármoles de Paros, Naxos, Pentélico, Tasos o Carrara. Es cierto que, en estas grandes exposiciones de anticuariado, nunca faltaban barrocas esculturas realizadas con mármoles de diferentes colores, pero parecían formar parte de simples modas tardías.

En 1958, las técnicas fotográficas primero y los análisis físico-químicos después permitieron acreditar científicamente las evidencias de las pigmen- 


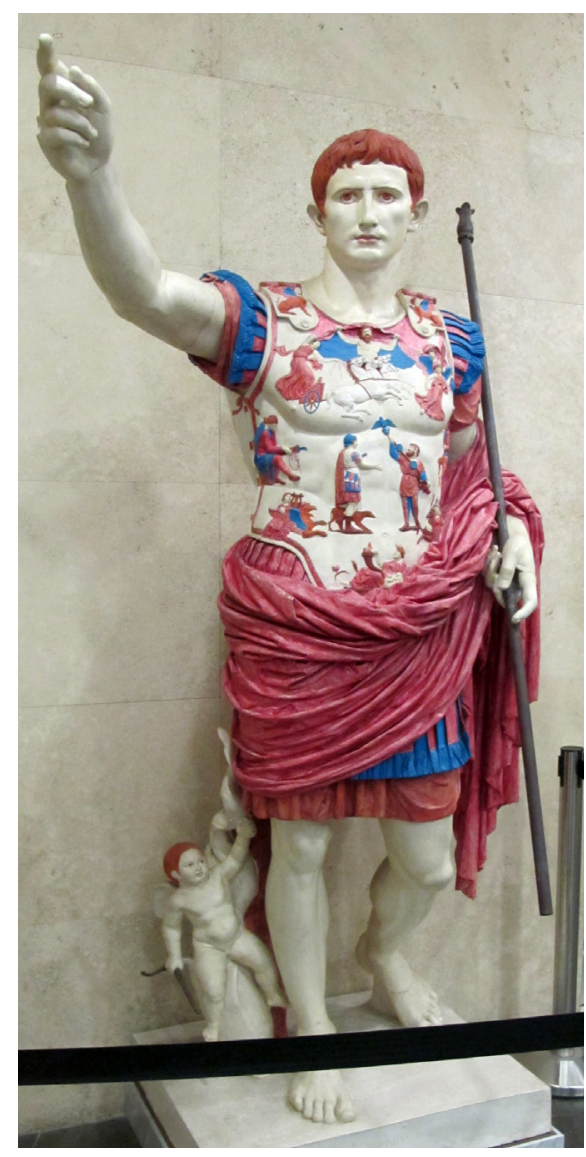

Propuesta polícroma del Augusto de Prima Porta de Paolo Liverani y Stefano Spada | fuente Wikimedia Commons taciones dando paso a su caracterización dentro de una nueva disciplina llamada arqueometría.

Las fotografías basadas en la luz ultravioleta permiten distinguir con claridad sobre el mármol los restos del color azul egipcio y los análisis químicos, tales como la microscopía electrónica de barrido mediante espectroscopia de rayos $X$ por dispersión de energía (SEM-EDX), de Infrarrojo por transformada de Fourier (FT-IR) y Raman, Infrarroja y Ultravioleta-visible-infrarrojo cercano, amplían el espectro a otros colores.

En los años 2003 y 2004 un equipo interdisciplinar e internacional de la Gliptoteca de Munich, Museos Vaticanos y Gliptoteca Ny Calsberg de Copenhage organizaron conjuntamente una gran exposición itinerante propuesta y dirigida por Vinzenz Brinkmann y Raimund Wünsche (2003). Llevaba por título Bunte Götter. Die Farbigkeit antiker skulptur y su catálogo incluía amplios estudios de detalle sobre piezas emblemáticas presentadas con restituciones completas de su policromía original: imágenes de la Acrópolis ateniense; del friso del tesoro de Syphnos en Delfos; diversos relieves funerarios áticos; cornisas, entablamentos y las excepcionales esculturas de los dos frontones del templo de Aphaia en Egina; sarcófagos helenísticos y una serie de grandes esculturas de referencia incluyendo entre ellas la imagen del Augusto de Prima Porta. Cuando la exposición fue presentada en los Museos Vaticanos en el año 2004 el catálogo fue traducido al italiano con un cambio de título: I colori del bianco. Policromia nella scultura antica (2004). La exposición fue expuesta también en Hamburgo en el año 2007 y llegaría en el año 2010 al Museo Arqueológico Regional de la Comunidad de Madrid con traducción al castellano del catálogo a partir de una pequeña variación del título original: El color de los dioses (Brinkmann y Bendala 2010).

\section{LA POLICROMÍA DEL AUGUSTO DE PRIMA PORTA}

Nuestro interés personal por esta cuestión surgió fundamentalmente a partir de una de las obras de arte estudiadas en esta exposición: el trabajo del profesor Paolo Liverani con estudio analítico de caracterización de pigmentos de Ulderico Santamaria y Fabio Morresi, y la copia escultórica de Stefano Spada (Liverani 2004, Santamaria y Morresi 2004, Spada 2004), sobre las evidencias pictóricas descubiertas sobre el bloque marmóreo de la gran escultura de Augusto encontrada en 1863 en la colina de Prima Porta, al norte de Roma. Se trata de una de las piezas más emblemáticas de la inmensa colección de grandes esculturas clásicas de los Museos Vaticanos después de que su descubridor, el conde Senni, la regalara al papa Pío IX (Grifi 1864).

Las evidencias de policromía en el cabello y pliegues del manto de esta escultura eran visibles a fines del siglo XIX (ver, por ejemplo, la restitución 
de L. Fenger 1886, citada en Brinkman 2010). Sin embargo, al presentar ahora juntas en el catálogo dos figuras, una con la escultura de Augusto tal como la conocemos hoy, realizada sobre un gran bloque del mejor mármol blanco de Paros de la variedad lychnites, y la nueva propuesta de reconstrucción polícroma a partir de las evidencias del estudio analítico, el espectador se queda perplejo. La restitución, a partir de evidencias científicas, nos muestra un contraste cromático entre el blanco de la coraza y también de la carnación blanca de cara, brazos y piernas, frente a los detalles de azul egipcio en las pteriges del faldellín que surge bajo la coraza o en detalles de la misma, el rojo bermellón del paludamentum y el ocre de la cabellera imperial, nos proporciona una extraña sensación de contraste fallido, de irrealidad, algo que el artista, teniendo en cuenta la estética de la época, plasmada no sólo en la plástica, sino en la poesía helenística y contemporánea, no pudo haber concebido como aspecto definitivo en la imagen original (Liverani 2004, 240-241).

Pero esto tiene una explicación. La propuesta original, que tuvo en cuenta estrictamente lo encontrado por los químicos sobre la superficie del mármol, es sumamente cauta en lo que a la evidencia científica se refiere (Liverani 2004, Santamaria y Morresi 2004, Spada 2004). Simplemente sitúa los pigmentos en las áreas donde se han encontrado. Su manera de aplicar la pintura fue a pincel, con los mismos pigmentos y el mismo aglutinante que los encontrados en las analíticas.

Se trata, pues, de un croquis volumétrico, el paso del croquis científico (tradicionalmente realizado como un dibujo en dos dimensiones, como el que encontramos en el catálogo de la exposición I colori del bianco. Policromia nella scultura antica, realizado por Stefano Spada) traspasado a la escultura. Lo que no apareció, las capas superiores de pintura, no se reprodujo, y por ello la escultura muestra unos colores planos muy estridentes. Por un lado, la imagen original ha sufrido un desgaste, al igual que se ha erosionado el soporte escultórico, que ha perdido las capas superiores de policromía. Por otro, las capas de pintura inferiores (las más cercanas a la superficie escultórica) se han llegado a conservar con una cierta intensidad, tal y como pasa con el azul y el rojo. En esta propuesta, además de los colores planos, se presentó una combinación de dos colores por veladura: el cinabrio y carmín de granza en el paludamentum, admitiendo el uso de al menos un procedimiento.

\section{LA PROPUESTA CROMÁTICA DEL AUGUSTO "TARRACONENSE". DIFERENCIA ENTRE TÉCNICA Y PROCEDIMIENTO}

A partir de nuestra experiencia como conservadores/restauradores, iniciamos una reflexión que nos ha permitido proponer y realizar una nueva policromía sobre la imagen a tamaño real en eco-resina y polvo de mármol de un 


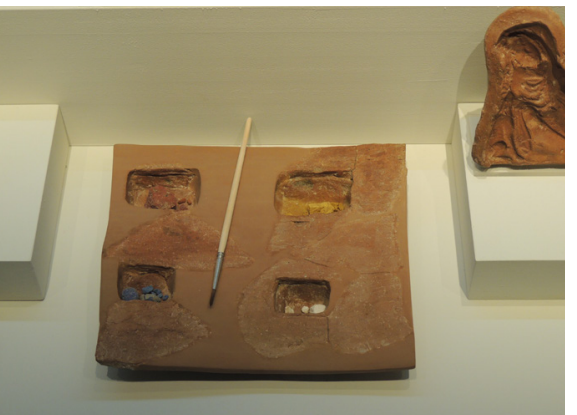

Paleta de color compartimentada de cerámica. Museo Arqueológico de Pella, s. II a. de C. | foto Taller MV Arte
Augusto de Prima Porta a raíz del encargo antes mencionado. Realizamos, en primer lugar, un molde de silicona, con contramolde de resina y fibra de vidrio, de la escultura en bronce del paseo arquelógico tarraconense. El resultado estético final se asemeja bastante al original por el alto contenido de polvo de mármol como aditivo de la resina.

Posteriormente le aplicamos una imprimación blanca, similar a la que tenía el original (a base de caseinato de cal con blanco de zinc, ya que, aunque el original contenía blanco de plomo en forma de cerusita, lo sustituimos por un pigmento sin toxicidad como es el óxido de zinc, para reducir el número de pigmentos tóxicos) y comenzamos a policromar con los pigmentos caracterizados por los químicos de los Museos Vaticanos, los colores que aparecen en la propuesta de Paolo Liberani, siguiendo los croquis de Stefano Spada (Spada 2004). Utilizamos rojo cinabrio, rojos y ocre amarillo de hierro, carmín de granza, azul egipcio, en una sola granulometría, ya que no encontramos en el mercado las bolas de esmalte que en tantas ocasiones se encuentran en las excavaciones arqueológicas, blanco de zinc en vez de cerusita y negro óxido de hierro.

El aglutinante que utilizamos fue temple al huevo, ya que en los análisis de caracterización de proteínas dio positivo en glicina y prolina, ambas proteínas presentes en este alimento (Spada 2004). Esta técnica, el temple al huevo, facilita tanto la aplicación de capas muy opacas, como sutiles veladuras, además de secar rápido.

Una vez aplicada esta primera capa, nos dispusimos a dar las siguientes capas perdidas. Seguimos utilizando los mismos pigmentos, pero al aplicar superposiciones, yuxtaposiciones y otros procedimientos ópticos, mediante veladuras, o mediante rallados y puntillismos, semeja que hemos utilizado más colores-pigmento, aunque no sea el caso.

No mezclamos los colores en una paleta, como se hace en la actualidad. Ni la palabra ni el concepto "paleta" existen en la tradición escrita e iconográfica greco-romana. Varrón (Agr. II, 17) nos dice que los pintores tenían arquetas donde guardaban los colores de cera en compartimentos separados. Un tipo de "paleta" como caja compartimentada podemos ver en el museo de Pella, en cerámica, del siglo III a. de C., o la que se ve representada en el Sarcófago de Kerch, del siglo I d. de C., en el Hermitage. Estos procedimientos en los que se utilizan varios colores que se suman de forma óptica, fueron descritos por Aristóteles (De sensu, 440 a) y discípulos suyos como por ejemplo Teofrasto (Sobre los colores, 794 b).

Así, nos parece evidente, por citar solo dos ejemplos de detalle, que el azul de las partes metálicas tuvo que ser tan solo una primera capa para una imitación metálica, o que la carnación nunca pudo ser blanca, sino que tendría 
un color frío de fondo y una serie de colores terrosos aplicados con veladuras. Esta ha sido la base conceptual y metodológica de nuestra nueva propuesta cromática: unir los conceptos de técnica y procedimiento.

Los conceptos de técnica y procedimiento normalmente no están diferenciados ni en el lenguaje habitual ni en la literatura especializada de las bellas artes. Las técnicas son los métodos que tiene que ver con el material, sobre todo con el aglutinante y sus aditivos. Por ejemplo, las técnicas del fresco, temple al huevo o encáustica, tienen que ver con el uso de la cal, de la yema de huevo o de la cera de abejas respectivamente. De manera que hidratar la cal, realizar morteros con ella de diferente granulometría para preparar la pared, o pintar con determinados pigmentos que aguantan la causticidad de la misma, son todos por igual métodos propios de la técnica del fresco. Los procedimientos son los métodos de aplicación de la pintura, o de la realización del dibujo: la pincelada en rayados, veladuras, empastes, usos del color, monocromías, elección de colores fríos o cálidos, métodos de proyectación, y de proyección: composiciones geométricas, narrativas, perspectiva aérea o lineal, proyecciones ópticas, etc. que son comunes a varias técnicas.

Por lo tanto, la propuesta del equipo de Paolo Liverani para la restitución cromática del Augusto de Prima Porta fue una propuesta técnica.

Nuestra propuesta, en cambio, fue técnico-procedimental, ya que, además de utilizar los pigmentos exactos (o aproximados en el caso del tóxico blanco de plomo que fue sustituido por óxido de zinc), y la técnica, también dedujimos los procedimientos que pudieron haber sido utilizados por los artistas creadores y los pusimos en práctica. No utilizamos más colores, sino que éstos surgieron ópticamente al utilizar la yuxtaposición y superposición de la paleta de pigmentos y tintes que Santamaria y Morresi identificaron en sus analíticas.

Crear la policromía de una gran escultura clásica de primer nivel exigía un artista de tanta calidad como la del escultor responsable del modelado y posterior tallado. Fueron obras realizadas en ocasiones por pintores de caballete, que seguían una serie de procedimientos de los que nos hablan las fuentes escritas y que se constatan en algunos ejemplos de pintura greco-romana. Para describir algunos de estos procedimientos que utilizamos, explicaremos a continuación nuestro trabajo sobre tres de las zonas policromadas: la imitación metálica, la carnación y la imitación del color púrpura del paludamentum.

\section{LA REPRESENTACIÓN METÁLICA}

Al leer las conclusiones de las pruebas fisicoquímicas del Augusto de Prima Porta (Santamaria y Morres 2004) en la descripción de algunos colores que se encuentran superpuestos, se menciona un amarillo de plomo que está 
1

"Finalmente el arte mismo adquirió autonomía y encontró la luz y las sombras exaltadas por la diferencia de los colores, con su alterna contraposición. Después se añadió el brillo (splendor), que no es aquí lo mismo que la luz. Llamaron tonos al intervalo entre la luz y las sombras y harmoge a la armonía en el tránsito entre los colores".
Propuesta polícroma de MV Arte: a la izquierda, primera capa de azul egipcio en las zonas de las pteriges; a la derecha, segunda capa de rayado con ocre amarillo y blanco para imitar los flecos de bronce | fotos Taller MV Arte sobre un azul egipcio. El equipo de los Museos Vaticanos lo consideró un repinte posterior (Liverani 2004, 239). En la estratigrafía se aprecian con claridad ambos colores, la capa de azul mucho más gruesa que la amarilla, sin ninguna capa de suciedad o barniz entre medias, lo que sí suele ocurrir en las estratigrafías de capas de repinte sobre policromías originales, llegando incluso a penetrar el color del repinte sobre el estrato original, cosa que en la muestra no ocurre.

Nosotros entendemos que se trata de la evidencia de un procedimiento de imitación metálica del bronce. En base a esta deducción, coloreamos de azul egipcio las partes en las que se encontró y que correspondían a zonas metálicas en la representación, y continuamos con rayado de colores ocre amarillo y blanco imitando el brillo metálico a la manera como Plinio (N.H. XXXV, 29) describe el brillo, no el iluminado del modelado, sino el punto brillante que tienen las superficies metálicas o pulidas, el splendor: Tandem se ars ipsa distinxit et invenit lumen atque umbras, differentia colorum alterna vice seseexcitante. Postea deinde adiectus est splendor, alius hic quam lumen. Quod inter haec etumbras esset, apellarunt tonon, commisuras vero colorem et transitus harmogen. ${ }^{1}$

En realidad, sabemos que la combinación de azul egipcio y amarillo plomo en imitaciones metálicas no es extraña y el avance de la investigación técnica y procedimental sobre policromías de arte clásico así lo confirma. Esta combinación se ha encontrado, por ejemplo, en el casco de la Atenea Lemnia del Museo del Bardo de Túnez (Kopczynski et ál. 2017). En este caso es el color amarillo (mimetita con trazas de vanadinita) el que se encuentra bajo el azul egipcio, que parece estar enfriando la imitación de oro. Esto nos recuerda inevitablemente a la denominada "selección oro", sistema de reintegración de elementos dorados en conservación-restauración de obras de arte, que
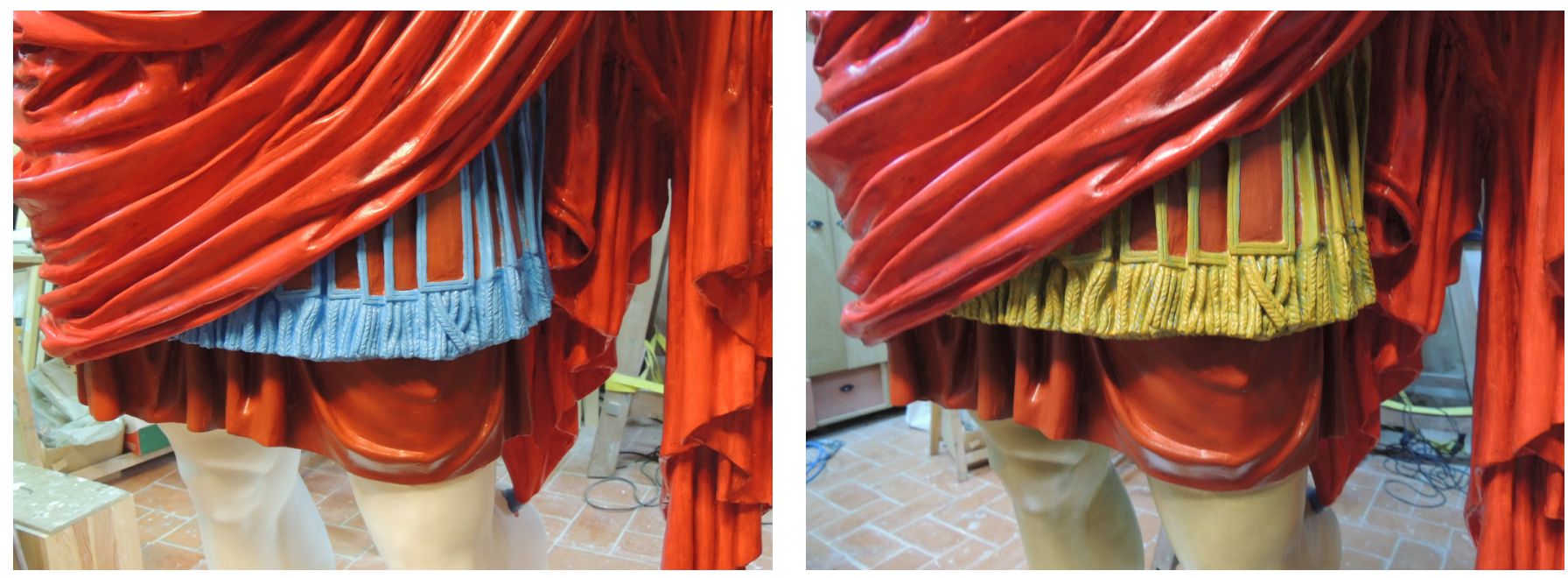
consiste en la aplicación a rayas mediante yuxtaposición entre un rojo óxido de $\mathrm{Fe}$, un amarillo ocre o cadmio, y un verde. En el mismo museo, encontraron una imitación de bronce en un codo de una escultura de gran tamaño en el que encontramos la misma combinación de azul egipcio, blanco de $\mathrm{Pb}$ y una capa inferior de amarillo ocre (óxido de Fe). En las conclusiones de este estudio dicen haber observado, en los ejemplos analizados, procedimientos como son la yuxtaposición, superposición (veladuras), iluminado y sombreado cromáticos. El iluminado y el sombreado constituyen los procedimientos para el modelado de los volúmenes.

En retratos de El Fayum también se han encontrado tonalidades frías como preparación para el pan de oro fino. En un retrato masculino de Tebtunis, para dorar con pan de oro una corona, se utilizó índigo como color base, no como bol, sino como tonalidad oscura que ayudase al oro a brillar por contraste (Salvant et ál. 2018). También se encontró azul egipcio como preparación para el pan de oro de un pendiente de mujer n. ${ }^{\circ}$ de catálogo AEIN 682 de El Fayum (Miliani et ál. 2010).

\section{LA CARNACIÓN}

El equipo de químicos dirigido por Ulderico Santamaría no detectó ningún resto de carnación, únicamente el dibujo de las pestañas y de la niña de los ojos del retrato y un resto de ocre rojo. Recordaba por tanto a una divinización, propia de las esculturas crisoelefantinas en las que se combinan detalles como la ropa o el cabello de pan de oro (en las originales era chapado) con piel de color blanco amarillento que recordaba el marfil original. Un ejemplo de este tipo de resultado estético lo podemos encontrar en la bellísima cabeza policromada de amazona de Herculano (Guidobaldi 2006) o en una Atenea Parthenos también del Museo del Bardo con tez blanca y cabello dorado con pan de oro (Kopczynski et ál. 2017).

En nuestra propuesta, al considerar que la escultura del Augusto de Prima Porta, aunque sea una representación evidente del princeps divinizado, no respondía, por el colorido de coraza y ropa, a una representación tipo crisoelefantina, decidimos policromar su carnación a la manera de la policromía de las Tanagras del Louvre (Jeammet, Knetch y Pagès-Camagna 2007). A estas esculturas de barro se les realizó análisis estratigráfico y se demostró que se habían aplicado, además de una capa de engobe blanca, como capa de preparación, tres capas de pintura para conseguir el aspecto de la piel: una gris verdosa (mezcla de negro de hueso, tierras magnésicas, esto es, arcillas amarillentas y de blanco de plomo), otra rosácea blanquecina y una tercera que correspondería a colores rojos como carmín de granza u óxidos de hierro, que se utilizarían en los enrojecimientos propios de los pómulos, la nariz, la barbilla y otros lugares que suelen ser más rosáceos que el 


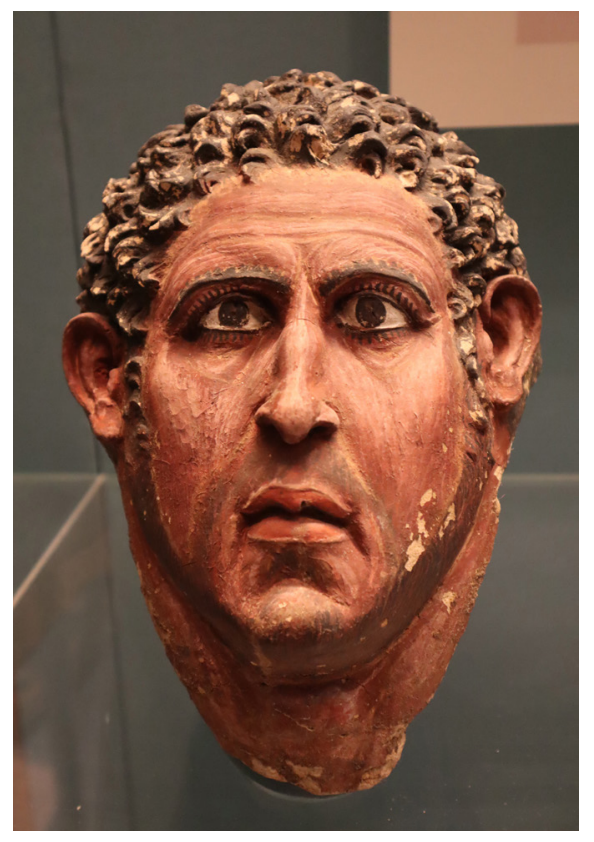

Máscara funeraria egipcia de yeso del British Museum, siglo II d. de C. Está policromada a rayados y veladuras bastante evidentes que actúan como suma de colores óptica por yuxtaposición y superposición | foto Taller MV Arte resto. Como paralelos, además de figuras cerámicas que soportan mejor la degradación, también utilizamos algunas máscaras de yeso del Egipto romanizado, como, por ejemplo, la que se encuentra en el British Museum, procedente de Dióspolis Parva (100-170 a. de C.) en el que vemos claramente la utilización de dos procedimientos: las veladuras y los rayados con bastante soltura y evidencia.

El mismo sistema de policromado de la carnación en las tanagras investigadas del Louvre, lo encontramos también en la pintura de iconos, por lo que analizamos también estos ejemplos. En la pintura de iconos se aplica, antes que nada, una capa verdosa, denominada panselinos por Dionisio de Fourna en su tratado del siglo XVIII, pero que recoge recetas muy anteriores, ya que la práctica pictórica bizantina no ha cambiado desde época romana, que se aplica a modo de boceto y de capa cromática a la vez, por lo que también a esta acción previa de aplicar el verde se le denomina proplasmos, es decir, boceto. En el siglo XIV, Ceninno Cennini también explica la manera de pintar carnaciones mediante la aplicación de una capa verdosa que él denomina verdaccio.

En 2014 el Augusto de Prima Porta se sometió a la técnica de la luminiscencia visible inducida (VIL), que permite detectar trazas de azul egipcio, y se encontraron también por la zona de carnación de la escultura en dosis muy pequeñas para, según sus interpretaciones, dar un tono más frío y brillante al color blanco y para oscurecer la piel (Liverani, Santamari y Verri 2018).

Son variados los ejemplos de utilización del azul egipcio para la carnación. Para sombrear, por ejemplo, se encontró en un fragmento escultórico de pie con sandalia del Museo del Bardo (Kopczynski et ál. 2017). Como pinceladas cromáticas, lo vemos en dos ejemplos del British Museum: un retrato de El Fayum (Verri, Oper y Devièse 2010, 47), con número de catálogo 1994, 0521.6:EA 74708, que representa a un hombre de época trajanea, en el que, mediante análisis de luminiscencia inducida (VIL), se detectó azul egipcio en la piel, en el blanco de los ojos y en el labio como sombra amoratada mezclada con el rojo (cinabrio o granza). También en una escultura, la cabeza Treud (Verri, Oper y Devièse 2010, 44-46), recientemente analizada para determinar su autenticidad, en la que hay azul egipcio en la carnación y en el blanco de los ojos, combinado con calcita, rojo ocre, amarillo ocre y negro carbón.

También se ha detectado azul egipcio en la carnación de otros retratos de El Fayum (Salvant 2017). Como capa previa, seguramente mezclado para hacer una capa fría, a modo de verdaccio lo encontramos en retratos de El Fayum, en la capa azulada o verdosa del fondo que en ocasiones se recorta alrededor de la figura pero a veces se pinta previamente como capa general de preparación, que sirve como fondo y como verdaccio (Delaney et ál. 2017; Salvant 2017). A simple vista se reconoce esta capa de preparación azulada o verdosa en multitud de retratos de El Fayum y en cuadros de dioses sobre 


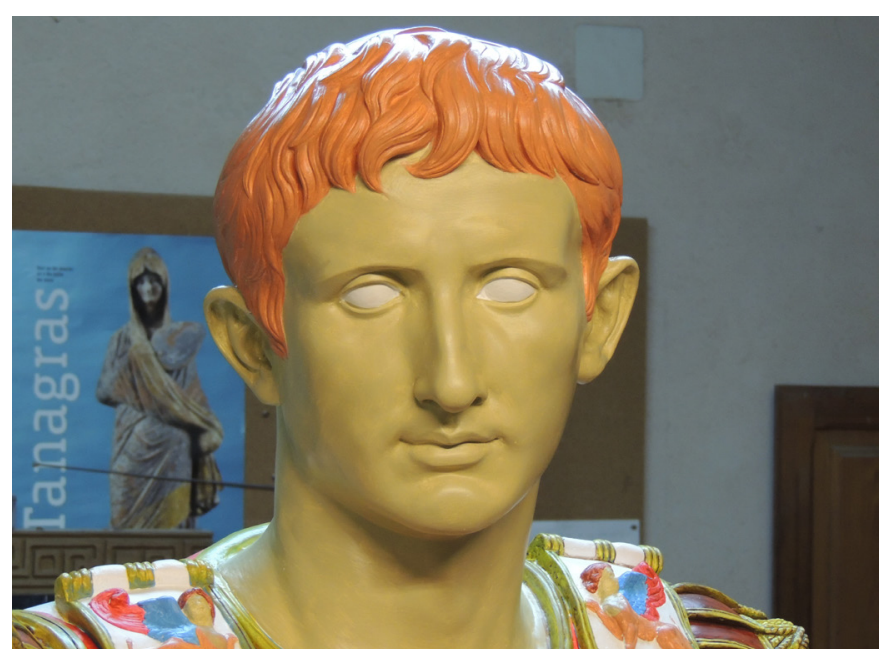

tabla como el de Isis, conservado en el Assiout College Museum (inv. 82), de procedencia desconocida (Rondot 2013). En las ocasiones en las que no se utiliza la capa de verdaccio, los colores utilizados para la carnación suelen proceder de óxidos de Fe rojizos y amarillos (jarosita) utilizados como cosmético en Roma y Egipto, y cinabrio para los labios, así como el azul egipcio para los sombreados o para enfriar el blanco de los ojos (Salvant 2017).

Por nuestra parte, policromamos el pelo y los ojos de manera similar a como lo hizo el equipo de los Museos Vaticanos, siguiendo sus mismas directrices. Para la carnación, sin embargo, aplicamos un panselinos a la manera de Dionisiso de Fourna (ocre amarillo, blanco y negro) en todas las zonas de piel de la escultura, aplicando, posteriormente, un ocre amarillo claro rosáceo (mezcla de tierras de Fe) y finalmente, dando rojizo con un óxido de Fe rojo en una muy fina veladura a modo casi de maquillaje. Ahora, de haber conocido estos últimos descubrimientos, (que precisamente ocurrían mientras realizábamos la policromía del Augusto tarraconense), utilizaríamos tierras de Fe y azul egipcio para las sombras como veladuras.

\section{PALUDAMENTUM}

El paludamentum, manto corto y pesado de color rojo intenso propio de las estatuas thoracatae, equivalente a la clámide de los griegos, era un atributo propio del mando militar legionario y en origen estaba realizado en lana. Con el tiempo, al convertirse en una prenda representativa y de prestigio característica de la iconografía imperial, se realizó también en seda. En la pintura mural macedónica y romana, los paludamenta están coloreados de un púrpura más cercano al rojo cinabrio que al púrpura morado-violeta propio del latus clavus o banda ancha distintiva de las togas senatoriales. En las analí-
Propuesta polícroma de MV Arte: primera capa de verdaccio o panselinos (a la izquierda); y veladuras con mezcla de óxidos de hierro ocres, rojos y

blanco (a la derecha) | fotos Taller MV Arte 
Propuesta polícroma de MV Arte: izquierda, primera capa de cinabrio en el paludamentum; derecha, añadido de veladuras de carmín de granza, toques de óxidos de hierro oscuros y blancos para el volumen en el paludamentum | fotos Taller MV Arte
Propuesta polícroma de MV Arte: Detalle de la coraza. Utilizando los mismos pigmentos caracterizados por Santamaria, aplicados mediante los procedimientos de rayado y veladura, surgen nuevos colores por yuxtaposición óptica | foto Taller MV Arte

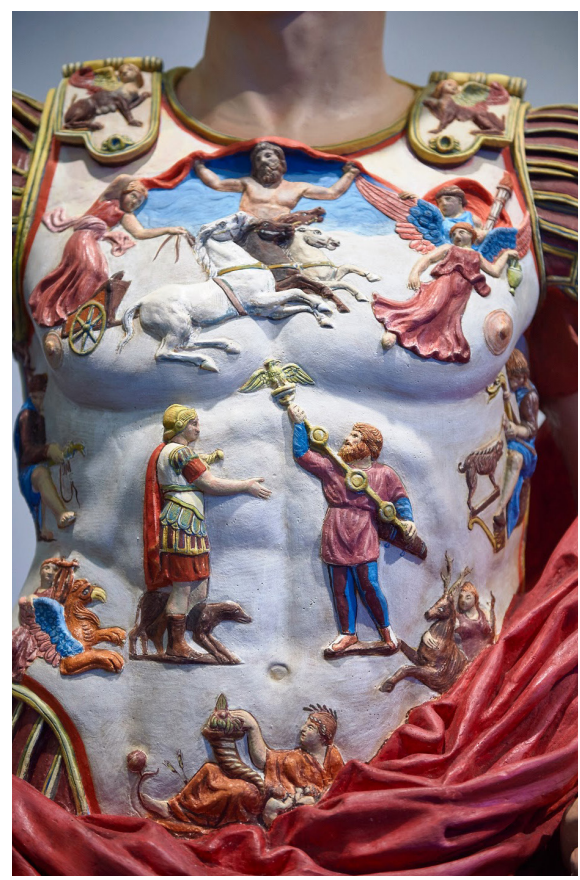

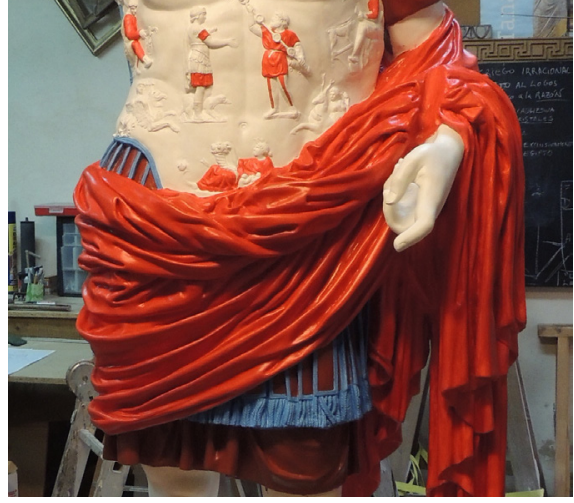

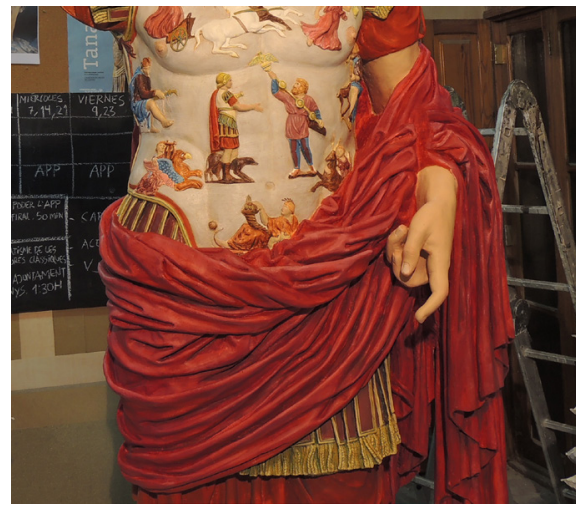

ticas los colores caracterizados se asemejaban más al primero. El color púrpura se puede considerar una gama más que un color. En realidad, según fuera la especie del molusco utilizado o el lugar de procedencia, o el propio proceso de obtención, las tonalidades variaban bastante.

Con estos datos realizamos la imitación de la tela teñida de púrpura partiendo de la propuesta de Paolo Liberani, aplicando primero un rojo cinabrio y después veladuras de un carmín de granza. Además incluimos tonalidades más claras y oscuras para intensificar el modelado de la tela, poniendo más densidad del color granza en el interior de los pliegues y, ayudándolo incluso, con un rojo amoratado de óxido de hierro. En las zonas más sobresalientes, por el contrario, aplicamos veladuras de blanco.

\section{CORAZA POLICROMADA}

La coraza anatómica, tal y como aparece en las analíticas, tuvo policromadas las distintas figuras en relieve que se reparten por la misma: dos esfinges en las hombreras, el Cielo, la Aurora llevando la cuádriga del sol precedida por Phosphoros, la estrella matutina y el Rocío, las provincias vencidas de Hispania y Galia; como imagen central, Marte (o Roma) y la loba recibiendo la devolución de un águila legionaria de manos un bárbaro parto, a los lados; debajo, Apolo con lira sobre un grifo y Diana sobre un ciervo; por último, en el extremo inferior Tellus, la tierra, con cuerno de la abundancia acompañada de Rómulo y Remo. En oposición a todo este recargado aparato figurativo, el fondo de la coraza fue blanco, quizás para que resaltasen mejor las distintas escenas y personajes (Liverani 2004).

Una coraza de color blanco remite a las griegas de tipo linotórax, realizadas con sucesivas capas de lino encolado. Un ejemplo sería la coraza blanca que lleva Alejandro en la batalla de Isos de la casa del Fauno en Pompeya, decorada únicamente en el pecho con una cabeza de medusa policromada. 
Pero estas corazas tenían una forma tubular muy característica con dos amplias hombreras y sin los detalles anatómicos de esta de Augusto que parece representar mejor una metálica probablemente de bronce.

La policromía sobre metal no fue rara en la Antigüedad, pero sobre el metal no se conservan bien las técnicas pictóricas entonces empleadas para la policromía, como era la cera o los temples. La exposición Bunte Götter/l colori del Bianco reunió sin embargo algunos elementos policromados pertenecientes a corazas griegas de bronce del siglo IV a. de C. como dos discos con cabezas de Gorgona, una con ojos policromados del Munchen Staatliche Antikensammlungen y otra del Antikenmuseum de Berlín con ojos, lengua y dentición, ambos ejemplos presentados por Hermann Born (Born 2004). En nuestra propuesta hemos mantenido el color blanco para la coraza, que en cualquier caso es una idealización figurativa.

\section{REFLEXIÓN FINAL}

Una realidad objetiva, base de nuestra propuesta de reconstrucción polícroma de la escultura del Augusto de Prima Porta, es la evidencia naturalista de la pintura conservada coetánea a Augusto y que convive con el lenguaje escultórico realista centrado en la mímesis, así como de los textos de poetas o filósofos contemporáneos. Por ejemplo, en las alegorías modeladas en la coraza del emperador, no existe una intención simplista de realismo si no que se representan los elementos con gran detalle escultórico y por lo tanto tendría que acabarse con una policromía en la misma línea como parte sustancial e inseparable de la creación artística de la escultura.

Tratamos así de reconstruir una obra de arte para la cual los artífices que estuvieron implicados en su realización utilizaron una serie de técnicas y procedimientos artísticos que debemos tener muy en cuenta. El estudio analítico de los aglutinantes y pigmentos utilizados es desde luego el primer paso imprescindible pero no podemos detenernos en ese punto si queremos divulgar al gran público el resultado de nuestras hipótesis. Nuestra intención ha sido aportar nuestra experiencia como profesionales de las artes plásticas, conocedores de las artes tradicionales, a la hora de presentar una propuesta artística final. Al fin y al cabo, en época antigua policromar lo hacían profesionales tan buenos como los escultores que modelaban los mármoles aunque, a diferencia del mundo helénico clásico, en Roma tuvieran que trabajar como profesionales anónimos.

En 2016 nos encargó el ayuntamiento de Braga otra copia con nuestra propuesta polícroma, en la que aplicamos los procedimientos pictóricos greco-romanos antes descritos utilizando una técnica moderna, el acrílico, para que resistiera al exterior.
Augusto policromado de Braga, Portugal | fuente Wikimedia Commons

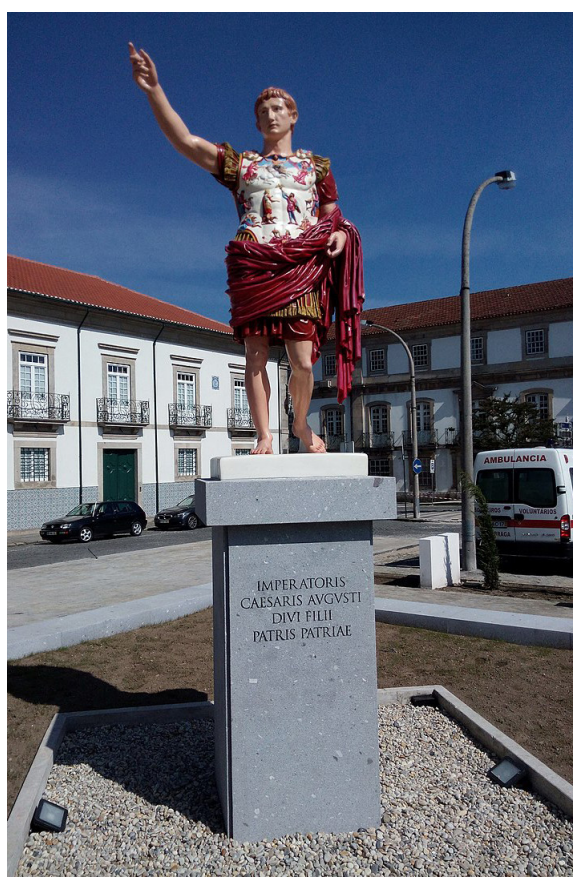




\section{BIBLIOGRAFÍA}

- Aristóteles, Alonso J. (trad.), Ferwerda, R., González de Durana, J., Vandrebroek, M., Kerejeta, M. J. (2006) Sobre Ios colores. Gasteiz: Bassarai Arte

- Aristóteles y Beare, J.I. (trad.) (2012) On Sense and the Sensible. Adelaide: University

- Aristóteles y Calvo Martínez J.L. (trad.) (1996) Los meteorológicos. Madrid: Alianza

- Bourgeois, B y Jockey, P. (2007) Le marbre, l'or et la couleur. Nouveaux regards sur la polychromie de la sculpture hellénistique de Délos. En: Descamps-Lequime S. (dir.) Peinture et Couleur dans le monde grec antique. París: Louvre, pp. 163-192

- Born, H. (2004) Anche i bronzi erano variopinti. En: Papini, M. y Polito, E. (trad.) I colori del bianco. Policromia nella scultura antica. Roma: De Luca Editori d'Arte, pp. 157162

- Brinkmann, V. y Bendala, M. (dir.) (2010) El color de los dioses. El colorido de la estatuaria antigua, Catálogo de la exposición en el Museo Arqueológico de la Comunidad de Madrid en Alcalá de Henares. Madrid: Serv. Publicaciones de la Comunidad de Madrid, 2010

- Brinkmann, V. (2010) ¿Una Armadura sobre la piel desnuda? El torso protoclásico de la Acrópolis de Atenas. En: Brinkmann, V. y Bendala, M. (dir.) El color de los dioses. El colorido de la estatuaria antigua, Catálogo de la exposición en el Museo Arqueológico de la Comunidad de Madrid en Alcalá de Henares. Madrid: Serv. Publicaciones de la Comunidad de Madrid, pp. 147-151

- Brinkmann, V. (2010) Los ojos azules de los persas: la escultura en color en época de Alejandro y el helenismo. En: Brinkmann, V. y Bendala, M. (dir.) El color de los dioses. El colorido de la estatuaria antigua, Catálogo de la exposición en el Museo Arqueológico de la Comunidad de Madrid en Alcalá de Henares. Madrid: Serv. Publicaciones de la Comunidad de Madrid, pp. 169-181

- Brinkmann, V., Østergaard, J.S., Kellner, S., KochBrinkmann, U. (2010) La coloración del retrato de Calígula. En: Brinkmann, V. y Bendala, M. (dir.) El color de los dioses. El colorido de la estatuaria antigua, Catálogo de la exposición en el Museo Arqueológico de la Comunidad de Madrid en Alcalá de Henares. Madrid: Serv. Publicaciones de la Comunidad de Madrid, pp 199-205

- Cennino Cennini y Olmeda Latorres, F. (trad.) (1988) El libro del arte. Madrid: Akal

- Delaney, J. K., Dooley, K. A. Radpour, R. y Kakoulli, I. (2017) Macroscale Multimodal Imaging Reveals Ancient Painting Production Technology and the Vogue in GrecoRoman Egypt. Nature.com/Scientific Reports, vol. 7, pp. 1-12. Disponible en: https://www.nature.com/articles/ s41598-017-15743-5 [Consulta: 20/11/2020]
- Dionysius of Fourna (1989) The Painter's manual. An English translation [from the Greek] with commentary of cod. gr. 708 in the Saltykov-Shchedrin State Public Library, Leningrad / by Paul Hetherington. Oakwood Publications

- Grifi, L. (1864) Intorno alla statua di Augusto recentemente trovata. En: Dissertazioni della Pontificia Accademia Romana di Archeologia, XV, pp. 417-434

- Guidobaldi, M.P. (2006) Una testa di amazzone dipinta. Forma Urbis, vol. 11, n. $^{\circ} 4$, pp. 4-7

- Jeammet, V., Knetch C. y Pagès-Camagna, S. (2007) La couleur sur les terres cuites helléni- stiques: Les figurines de Tanagra et Myrina dans la collection du musée du Louvre. En: Descamps-Lequime, S. (dir.) Peinture et Couleur dans le monde grec antique. París: Louvre, pp. 193-204

- Jenofonte y Zaragoza Botella, J. (trad.) (1993) Recuerdos de Sócrates. Madrid: Gredos

- Kopczynski, N., de Viguerie, L., Neri, E. y Nasr, N. (2017) Polychromy in Africa Proconsularis: investigating Roman statues using X-ray fluorescence spectroscopy. Antiquity, vol. 91, n. ${ }^{0} 358$, pp.139-154

- Miliani, C., Daveri, A., Spaabaek, L., Romani, A., Manuali, V., Sgamellotti, A. y Brunetti, B.G. (2010) Bleaching of red lake paints in encaustic mummy portraits. Applied Physics A, n. ${ }^{\circ} 100$, pp. $703-11$

- Liverani, P. (2004) L'Augusto di Prima Porta. En: Papini, M. y Polito, E. (trad.) I colori del bianco. Policromia nella scultura antica. Roma: De Luca Editori d'Arte, pp. 235-242

- Liverani, P. (2008) La policromia delle statue antiche. En: Noguera J.M. y Conde, M.E. (dir.) Escultura romana en Hispania V. Actas de la reunión Internacional. Murcia: Tabularium, pp. 65-85

- Liverani, P. (2010) New evidence on the Polychromy of Roman Sculpture. En: Brinkmann, V., Primavesi, O. y Hollein, M. (ed.) Circumlitio. The polychromy of antique and Mediaeval Sculpture. Munich: Hirmer Verlag, pp. 290-302

- Liverani, P., Santamaria, U. y Verri, G. (2018) La quarta dimensione della scultura: il colore. En: Márquez, C. y Ojeda, D. (dir.) Escultura Romana en Hispania VIIIHomenaje a Luis Baena de Alcázar (Córdoba 2016). Córdoba: Universidad de Córdoba, pp. 121-138

- Luciano de Samosata y Zaragoza Botella, J. (trad.) (1990) Obras III. Madrid: Gredos

- Østergaard, J.S. (2010) El Calígula de la Gliptoteca de Ny Calsberg de Copenhague. La reconstrucción de las áreas policromadas de un retrato romano. En: Brinkmann, V. y Bendala, M. (dir.) El color de los dioses. El colorido de la estatuaria antigua, Catálogo de la exposición... Madrid: Serv. Publicaciones de la Comunidad de Madrid, pp. 187193 
- Plinio y Torrego, E. (trad.) (1987) Historia natural. Textos de Historia del Arte. Madrid: Visor, 1987

- Polibio y Díaz Tejera, A. (trad.) (1986) Historias. Madrid: Consejo Superior de Investigaciones Científicas

- Rondot, V. (2013) Derniers visages des dieux d'Egypte. Paris: Louvre, 2013

- Rossini, O. (2010) I colori dell'Ara Pacis. Storia di un esperimento. Archeomatica, vol.1, n. ${ }^{\circ} 3$, pp. 20-25

- Santamaria, U. y Morresi, F. (2004) Le indagini scientifiche per lo studio della cromia dell'Augusto di Prima Porta. En: Papini, M. y Polito, E. (trad.) / colori del bianco. Policromia nella scultura antica. Roma: De Luca Editori d'Arte, pp. 243-248

- Stege, H.; Fiedler, I. y Baumer, U. (2010) Análisis de los pigmentos y aglutinantes en la policromía del retrato de Calígula. En: Brinkmann, V. y Bendala, M. (dir.) El color de los dioses. El colorido de la estatuaria antigua, Catálogo de la exposición... Madrid: Serv. Publicaciones de la Comunidad de Madrid, pp. 194-196

- Salvant, J., Williams, J., Ganio, M., Casadio, F., Daher, C., Sutherland, K., Monico, L., Vanmeert, F. De Meyer, S., Janssens, K., Cartwright, C. y Walton, M. (2017) A Roman Egyptian Painting Workshop: Technical Investigation of the Portraits from Tebtunis, Egypt. Archaeometry, vol. 60, n. ${ }^{\circ} 4$, pp. 815-833

- Spada, S. (2004) Restauro e riconstruzione della policroma dell'Augusto di Prima Porta. En: Papini, M. y Polito, E. (trad.) I colori del bianco. Policromia nella scultura antica. Roma: De Luca Editori d'Arte, pp. 249-252

- Stavru, A. (2015) Graphike, andriantopoiia e thorakopoiia nell' Augusto di Prima Porta. Una lettura ecfrastica di Xenophon. Mem. III 10. En: Günther, H.C. (ed.) Augustus und Rom: 2000 Jahre danach. Nordhausen: Traugott Bautz, pp. 243-280

- Teofrasto y Solana Dueso, J. (trad.) (1989) Sobre las sensaciones. Madrid: Anthropos

- Theopilus, Hawthorne, J.G. y Stanley Smith, C. (trad.) (1961) On divers arts. London: Thomas Nelson and sons

- Tracking Colour (2010) The polychromy of Greek and Roman sculpture in the Ny Carlsberg Glyptotek. Disponible en: http://www.trackingcolour.com/assets/d/0/1207/Tracking_ Colour_2_final.pdf [Consulta: 23/11/2020]

- Tsatsouli, K. y Nicolau, E. (2017) The ancient Demetrias figurines: new insights on pigments and decoration techniques used on hellenistic clay figurines. STAR. Science and Technology of archaeological research, vol. 3, pp. 1-17

- Varrón, M.T. y Tirado Banedí, D. (trad.) (1992) De las cosas del campo. (2a edición). México D. F.: Universidad Nacional Autónoma de México
- Verri, G., Oper, T. y Devièse, T. (2010) The 'Treu Head': a case study in Roman sculptural polychromy. The British Museum Technical Research Bulletin, vol. 4, pp. 39-54

- Vitrubio y Oliver Domingo, J.L. (trad.) (2004) Los Siete Libros de Arquitectura. Madrid: Alianza Editorial

- Williams, M.F. (2005) The new Posidippus: realism in Hellenistic sculpture, Lysippus and Aristotle's aesthetic theory (P. Mil. Vogl. VIII.309, Pos. X.7-XI.19 Bastianni=6270AB). Leeds International Classical Studies, vol. 4, pp. 1-29

- Zahonero, E. (2013) Los procedimientos pictóricos en la época helenística y romana. Un ejemplo de museografía didáctica. Tesis doctoral, Universitat Rovira i Virgili, Tarragona. Disponible en: http://repositori.urv.cat/estatic/ TDX0011/ca_TDX1202.html [Consulta: 19/11/2020]

- Zahonero, E. y Mendiola, J. (2015) La policromía del Augusto de la Prima Porta, una propuesta procedimental. En: August i les provincies occidentals, Actes del $2^{\circ}$ Congrés Internacional d'Arqueología i Món Antic (Tarragona 2014). Tarragona: Fundació Privada Mutua Catalana, pp. 85-91

- Zanker, P. (1987) Augusto y el poder de las imágenes. Madrid: Alianza Editorial 